\title{
A Cost-Effective Wind Power-Driven Ro Plant for Treatment of Brackish Water
}

\author{
Shivendra Verma, Ramsingh Meena, Anurag Mudgal* \\ Department of Mechanical Engineering, School of Technology, Pandit Deendayal Petroleum University, \\ Gandhinagar, India \\ Email: anurag.mudgal@sot.pdpu.ac.in
}

Received November 2015

\begin{abstract}
Desalination has often been perceived as a high cost means of producing water. Reason being that some of the water treatment methods use electricity to run a pump as in Reverse Osmosis system and some uses thermal energy to produce steam as in Multi Effect Distillation. High cost and less availability of conventional fuels has attracted the focus of researchers to explore other unconventional means and methods to purify water. This paper explores the possibility of using wind power for water treatment. In costal countries, tremendous wind power is available at the coastline which may be used to drive a RO plant. In India particularly, the average wind speed calculated along the coastlines of Gujarat state gives a fair idea about potential of energy that can be generated. This energy can be harnessed to run a rotating pump, or a piston-cylinder arrangement coupled with $\mathrm{RO}$ module to provide the necessary pressure required to push saline water through the membrane. Along the western coast of India there is an abundance of wind energy to capitulate high amount of energy in terms of electrical Power. If the rotor diameter is 4 feet $(1.3 \mathrm{~m})$ and located at a height of 8 feet $(2.5 \mathrm{~m})$, each wind turbine may produce power of around $2 \mathrm{KW}$. This power may be used to run the reciprocating pump which provides pressure to the RO Apparatus. The paper describes recent advancements in the wind industries technology to produce electrical energy at low cost but it concentrates more on coupling wind energy directly with RO module to save energy conversion cost which is a seldom or different approach than converting electrical energy to mechanical energy for running of RO system.
\end{abstract}

\section{Keywords}

Wind Power, Reverse Osmosis, Desalination

\section{Introduction}

Water scarcity and population in the present world is increasing day by day. Fresh water resources are limited and modern lifestyle is leading to increase per capacity water consumption desalination can provide a solution to meet required surplus amount. Desalination is mostly achieved by either RO (Reverse Osmosis) or thermal desalination. Both the processes have drawbacks as RO is efficient but uses costly electrical energy whereas ther-

\footnotetext{
"Corresponding author.
}

How to cite this paper: Verma, S., Meena, R. and Mudgal, A. (2015) A Cost-Effective Wind Power-Driven RO Plant for Treatment of Brackish Water. Journal of Geoscience and Environment Protection, 3, 40-46. 
mal desalination is inefficient but uses less expensive thermal energy. This paper mostly focuses on running the RO plant with the use of unconventional energy source. The RO plant would be utilised to purify mostly the brackish water available in rural areas of India, where availability of electricity is less or intermittent which is required to run a plant is a challenge.

The idea of using unconventional energy to operate desalination plant aims on meeting future demand. One of the major factors affecting the total cost of water production by any type of desalination process is the energy cost. Typically in a reverse osmosis plant, 3 to $10 \mathrm{kWh}$ of electric energy is required to produce one cubic meter of freshwater from seawater [1]. Since cost of renewable energy is generally independent of fossil fuel prices, the cost fluctuations due to energy cost instabilities can be avoided if the system is operated with renewable energy technologies. Furthermore the energy required for pressuring feed water can be significantly reduced if high pressure or desired pressure is generated with the help of unconventional energy source.

\section{Objectives}

For rural applications where decentralized supply of water is needed, the plant should have the following characteristics [2]:

1) It should be small, capable of producing a few cubic meters of treated water per day to satisfy local demands.

2) It should be energy efficient and should run on local energy sources, wind energy preferably (as per this paper).

3) It should be cost effective and affordable by rural communities.

4) It should be rugged, robust and easy to maintain. In case of a fault, a rural mechanic should be able to repair it easily.

\section{Problems Faced with Generating Pressure from Motor (Electricity Provided from Wind Turbine)}

Installation of underground laid cables which transmits the electricity generated from individual wind mill to the main grid of the plant requires a large capital.

At some places the temperature may drastically change which may lead to destruction of cables (Figure 1) if not protected. Underground rodents which may live in nearby area may destroy the cables. In this paper it provides the remedies to solve the problems described above. As we are not using electricity so there is no need of underground cables. For future perspectives, if applied for large scale applications like wind farm this technology could be used with sundry changes. Different wind mills will have their own reservoir tanks (treated purified water). The water source would be brackish water, brought to individual wind mills with the help of pump (booster pump). The further processing is done by the procedure as described below.

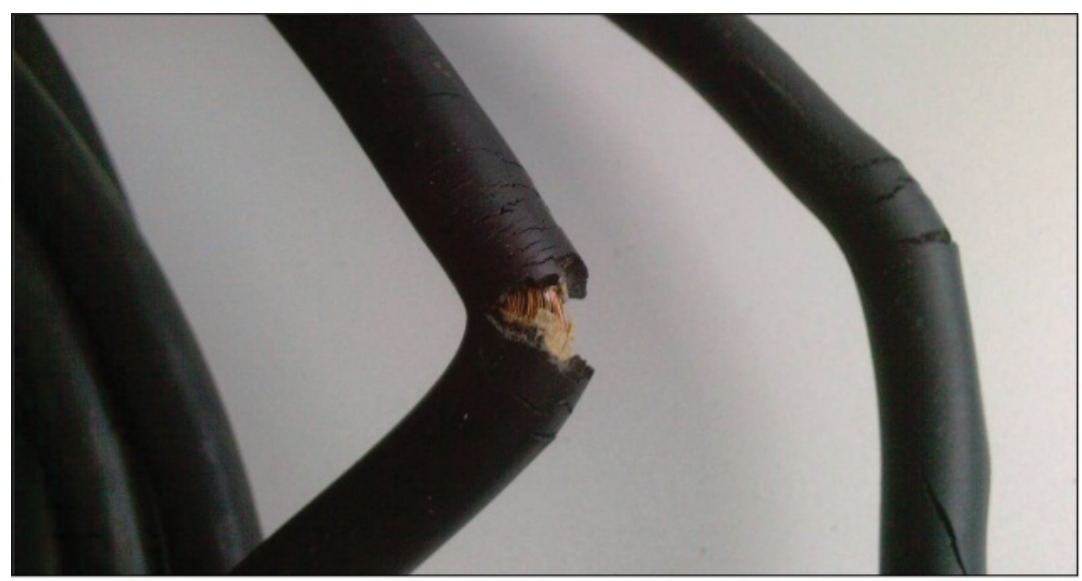

Extreme temperatures - both hot and cold - can take their toll on cables.

Photo courtesy of Helukabel USA

Figure 1. Destruction of cable. 


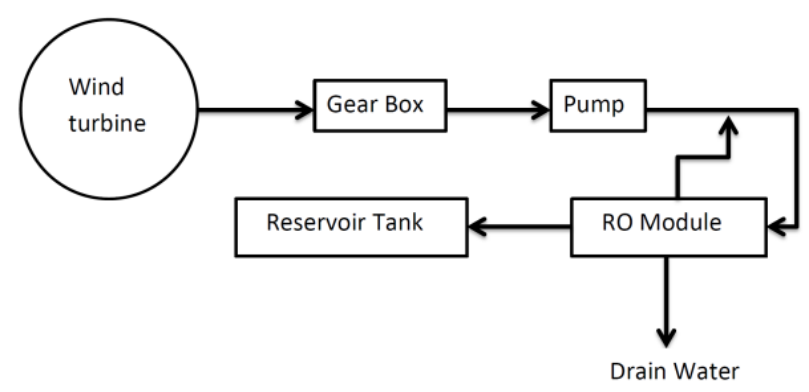

Figure 2. Flow diagram of the process.

\section{Methodology}

The main components of the RO system may be summarised as follows:

1) RO module.

2) Wind turbine.

3) Pump (run by wind turbine).

4) Wind turbine gearbox.

As shown in above flow diagram (Figure 2), we couple the shaft of the wind mill to pump with the help of gear box attached to it. The shaft of the pump rotates with the help of wind mill and the pumps work without generation of electricity. The wind will is installed at a height of about 8 feet about the ground; distance of the centre of hub in wind mill is 8 feet above the ground. Shaft of the wind mill is horizontal, connected to bevel gear which converts the horizontal rotational movement to vertical rotational movement, which is further connected to another gear box. The shaft of this gear box is coupled with the shaft of motor which provides the pressure required by the RO module. Below shows armature of the pump (Figure 3) is removed which runs with the help of electricity. Here instead we are not converting electrical energy generated from wind turbine to run the pump. Instead we couple the shaft of the pump to the shaft of wind turbine via a gear box which provides sufficient rotation to generate enough pressure in RO module.

\section{Calculations}

\subsection{Calculating Wind Power Potential}

A German physicist Albert Betz concluded in that no wind turbine can convert more than $59.3 \%$ of the kinetic energy of the wind into mechanical energy turning a rotor. To this day, this is known as the Betz Limit or Betz law [3]. The theoretical maximum power efficiency of any design of wind turbine is 0.59 (i.e. no more than $59 \%$ of the energy carried by the wind can be extracted by a wind turbine) [4] [5].

$$
P_{\text {avail }}=\frac{1}{2} \rho A v^{3} C_{p}[\text { Power Available }]
$$

\subsection{Calculations with Given Data}

The following data:

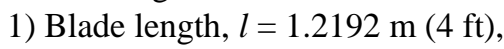

2) Wind speed, $v=12 \mathrm{~m} / \mathrm{sec}$,

3) Air density, $\rho=1.23 \mathrm{~kg} / \mathrm{m}^{3}$,

Power coefficient, $C_{p}=0.4$.

Inserting the value for blade length as the radius, calculate swept area (Figure 4).

$$
\begin{aligned}
\text { Area } & =\pi \times r^{2} \\
& =\pi \times 1.2192^{2} \\
& =4.6674 \mathrm{~m}^{2}
\end{aligned}
$$

We can then calculate the power converted from the wind into rotational energy in the turbine. By using Equ- 
ation (1), we get.

$$
\begin{aligned}
& =1 / 2 \times 1.23 \times 4.6674 \times 12^{3} \times 0.4 \\
& =1.984 \mathrm{KW} \\
& =2.6605 \mathrm{Hp}
\end{aligned}
$$

The power coefficient is not a static value as defined in the main question; it varies with the tip speed ratio of the turbine. Tip speed ratio is defined as [3] [6]:

$$
\lambda=\frac{\text { blade tip speed }}{\text { wind speed }}
$$

$\lambda$ (tip speed ratio) changes as wind speed is variable quantity, if it changes so does $C_{p}$ as represented by the graph (Figure 5).

The blade tip speed can be calculated from the rotational speed of the turbine and the length of the blades used in the turbine using the following equation:

$$
v=2 \pi r \times R P M \times(60 / 1000) \mathrm{km} / \mathrm{hr}
$$

\subsection{Aggregating the Costs}

\begin{tabular}{cc}
\hline Machine Equipments & Costs (Rs.) \\
\hline Wind turbine gearbox, structure, pump set & 65,000 \\
Pump & 2150 \\
RO module & 2200 \\
TDS meter & 700 \\
Ph meter & 850 \\
Auxiliary investments & 1000 \\
Total & $71,900(1105.33 \$)$ \\
\hline
\end{tabular}

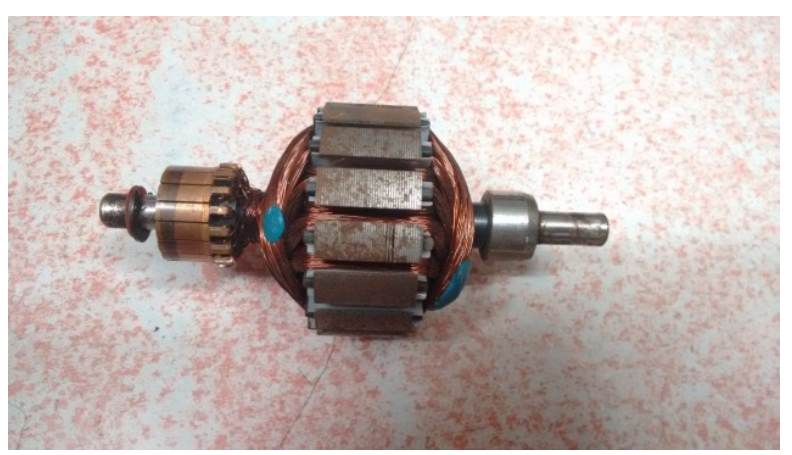

Figure 3. The armature used in pump.

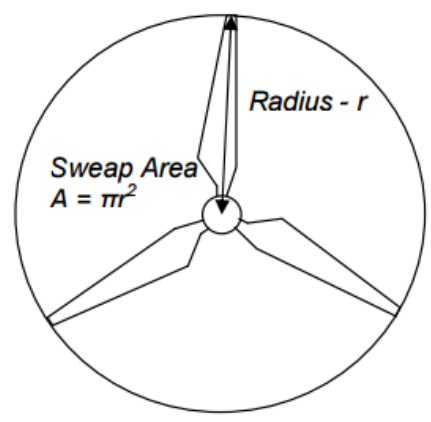

Figure 4. Schematic diagram of wind turbine. 
Representative $\mathrm{C}_{\mathrm{p}}-\lambda$ curve

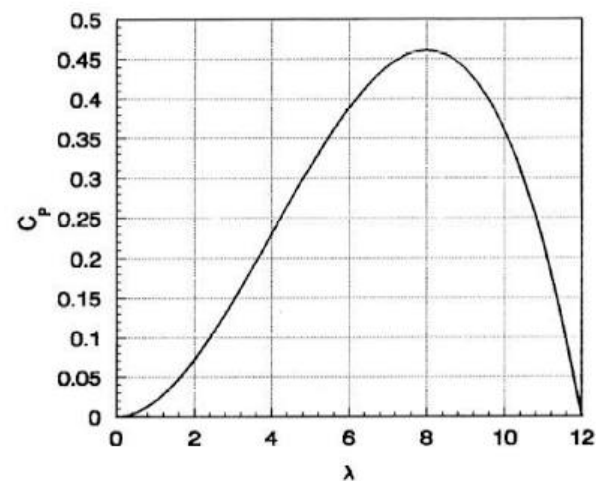

Figure 5. Relationship $C_{p}$ vs $\lambda$.

\section{R0-Module Specifications}

Membrane Type: Thin film Composite Membranes, Size (approximate): 2.75" Diameter × 15.74".

\section{Pump Specifications}

Design: Positive displacement 3 chamber Diaphragm Pump (Figure 6), Motor: Permanent motors, Ball bearing, water flow: 14 LPH, Inlet Pressure Max: 40 psi, Outlet Pressure: 125 psi, Rotation Speed rate: $800 \pm 50$ rpm.

\section{Gear Box}

To calculate the type and number of teeth in the gears used, we take the help of rpm and use it in the following equation:

$$
S 1 \times T 1=S 2 \times T 2
$$

$S 1=$ Speed of driver gear $(\mathrm{rpm}) \rightarrow 94-100$,

$S 2=$ Speed of driven gear $(\mathrm{rpm}) \rightarrow 800$,

$T 1=$ Number of teeth in driver gear,

$T 2=$ Number of teeth in driven gear.

$T 1 / T 2=800 / 100$

The gear ratio required is $8: 1$.

To get an optimum desired rpm we use helical gears which operate more smoothly and quietly compared to spur gears due to the way the teeth interact. The thrust load varies directly with the magnitude of tangent of helix angle. Helical gears can be used to adjust the rotation angle by $90 \mathrm{deg}$. When mounted on perpendicular shafts. Its normal gear ratio range is 3:2 to 10:1. The gear box could be considered as hub of the mechanical mechanism as it provides required rpm to the shaft of motor which generates pressure to inlet water to pass through RO Module.

\section{Break-Even Analysis}

With the help of the setup arranged we generate 7 to 8 litres per hour of mineralised water if we cost the customer Rs.1/lt $(0.015 \$ / \mathrm{lt})$.

7 lt $\times 24$ hours $=$ Rs.168/day

$168 \times 30$ days $=$ Rs. 5 , 040/-

When we increase the rate which includes maintenance of the setup by $3 \%$ annually and increase the cost by Rs.1/lt/year. We get the graph as given below (Figure 7).

\section{Conclusions}

Above calculated Break-Even analysis provides you with brief of the result as well as conclusion. The treated 


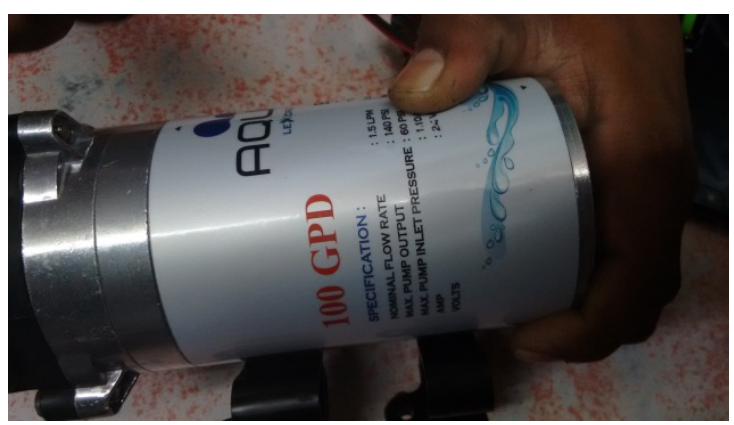

Figure 6. Pump used to generate pressure.

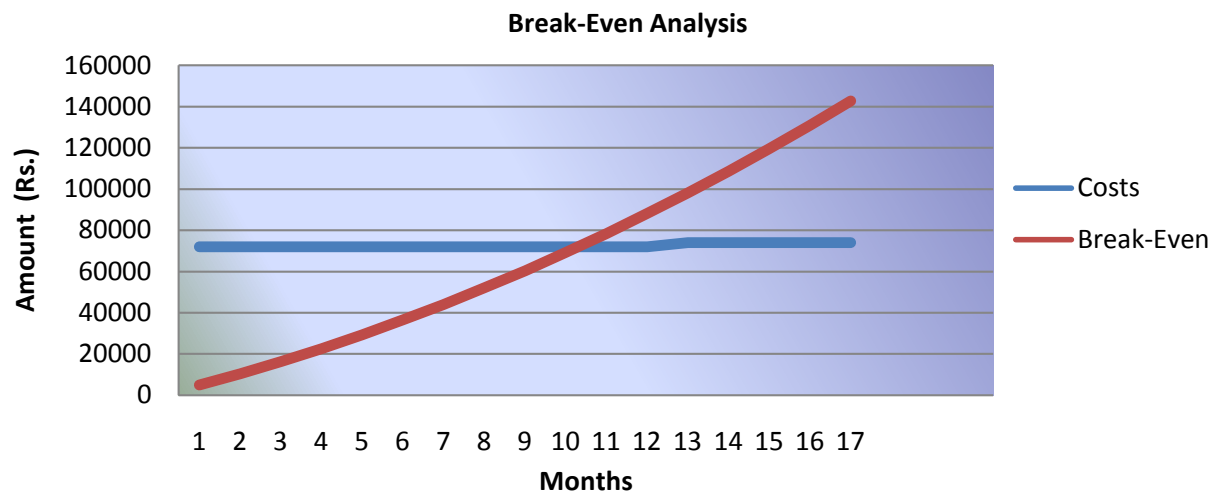

Figure 7. Graph showing break-even analysis.

water obtained has fewer amounts of dissolved salts and the cost invested in installation and running of the setup is recovered in less than a year, which can be seen in graph (Figure 7).

The power generated is $2 \mathrm{KW}$ with the help of single setup. This power can be used to run the reciprocating pump which provides pressure to the RO Apparatus. If the experiment is applicable for mass production then the money generated in terms of profit can be further used, more equipment can be planted in many parts of rural areas. Money invested could be recovered in 10 months (Figure 7).

\section{Future Work}

The money collected as profit would be further invested in instalments of the machine in various other places which are deprived of clean water or cannot have enough capital to have water treatment method. The places could be villages where there is dearth of electricity, which is required by common water treatment methods. A prototype is proposed to be fabricated at PDPU (Pandit Deendayal Petroleum University), India. The project proposal is being submitted as ORSP (Office of Research \& Sponsored Programs) cell to finance the fabrication work.

\section{Acknowledgements}

We acknowledge the support from PDPU (Pandit Deendayal Petroleum University) in terms of Laboratory Facilities and financial support to carry out this research and presenting the paper.

\section{References}

[1] Dashtpour, R. and Al-Zubaidy, S.N. (2012) Energy Efficient Reverse Osmosis Desalination Process. International Journal of Environmental Science and Development, 3.

[2] Sen, P.K., Sen, P.V., Mudgal, A., Singh, S.N., Vyas, S.K. and Davies, P. (2011) A Small Scale Multi-Effect Distillation (MED) Unit for Rural Micro Enterprises: Part 1-Design and Fabrication. Desalination 27915-26. http://dx.doi.org/10.1016/j.desal.2010.11.003 
[3] Bird, J. (2007) Basic Engineering Mathematics. Elsevier Ltd.

[4] Royal Academy of Engineering (2010) Wind Turbine Power Calculations. RWE Npower Renewables, Mechanical and Electrical Engineering Power Industry.

[5] Ragheb, M. and Ragheb, A.M. (2011) Wind Turbines Theory-The Betz Equation and Optimal Rotor Tip Speed Ratio. In: Carriveau, R., Ed., Fundamental and Advanced Topics in Wind Power. http://dx.doi.org/10.5772/21398

[6] Bird, J. (2007) Engineering Mathematics. 5th Edition, Elsevier Ltd.

\section{Appendix}

\begin{tabular}{ccc}
\hline Symbol & Unit & Description \\
\hline$\rho$ & $\mathrm{Kg} / \mathrm{m}^{3}$ & Density \\
$\pi$ & -- & $\operatorname{Pi}(3.14)$ \\
$\mathrm{A}$ & $\mathrm{m}^{2}$ & Area \\
$\lambda$ & -- & Tip Speed Ratio \\
$r$ & $\mathrm{~m}$ & Radius \\
$C_{p}$ & -- & Power coefficient \\
\hline
\end{tabular}

